\title{
O CICLO VICIOSO DA POBREZA E INSEGURANÇA ALIMENTAR EM GOIÂNIA/GO, BRASIL
}

\author{
Cleyzer Adrian da Cunha ${ }^{1}$ \\ Ana Caroline Dias Caixeta ${ }^{2}$ \\ Alcido Elenor Wander ${ }^{3}$
}

\begin{abstract}
Resumo
Este trabalho verifica a relação entre insegurança alimentar e a renda monetária dos catadores de material reciclável em algumas cooperativas de Goiânia/GO. Para tanto, foram entrevistados 44 cooperados, em que se obteve o perfil socioeconômico e alimentar deste grupo. Além disso, por meio da modelagem econométrica Logit verificou que a melhoria no nível de renda não acarreta uma diminuição da probabilidade da incidência de insegurança alimentar, contrariando assim a hipótese inicial do trabalho. Dentro das variáveis analisadas, a que de maneira significativa afeta a insegurança alimentar no estudo é a variável dummy que mede a participação dos catadores em programas governamentais, evidenciando a importância de políticas públicas como importante mecanismo de melhoria do padrão de vida de grupos vulneráveis.
\end{abstract}

Palavras-chave: Insegurança alimentar. Ciclo vicioso da pobreza. Modelo Logit.

1 Economista (PUC-Minas), mestre e doutor em Economia Aplicada pela (UFV). cleyzercunha@gmail.com.

2 Economista (UFG) e Mestre em Agronegócio (UFG). caroline.nca@gmail.com.

3 Agrônomo graduado na University of Kassel, mestre e doutor em Ciências Agrárias (Concentração: Economia Agrícola) pela University of Goettingen. alcido.wander@embrapa.br. 


\section{Introdução}

Atualmente, o descarte final dos resíduos sólidos tanto de domicílios quanto de indústrias é um dos grandes problemas ambientais brasileiros, tendo em vista que muitas das cidades brasileiras ainda não adequaram a gestão do lixo às regras da Política Nacional de Resíduos Sólidos (PNRS) (BRASIL, 2010). A meta dessa legislação - instituída pela Lei no 12.305, de 12 de agosto de 2010 - era que até agosto de 2014 todos os locais impróprios para o despejo do lixo fossem erradicados no Brasil, bem como que estes fossem transformados em aterros sanitários, instalações ambientalmente adequadas para o manejo e depósito de rejeitos. Dentre as principais ações, a legislação também determina a implantação de reciclagem, reuso, compostagem, tratamento do lixo e coleta seletiva nos municípios (BRASIL, 2010).

Esse descarte, se realizado de forma incorreta, pode gerar graves problemas socioambientais. Segundo Nogueira Junior (2006), o descarte incorreto do lixo pode levar a três tipos de problemas: o ambiental, o sanitário e o social. O primeiro problema, o ambiental, se dá pela poluição do solo e da água. O sanitário é ocasionado pela proliferação de vetores que transmitem doenças infectocontagiosas. E, atualmente, nos "lixões" ainda persiste o problema social que é a dependência econômica de pessoas que sobrevivem da coleta de material reciclável, como: papelão, vidro e plástico.

A partir deste contexto econômico e social surgiram as associações, as cooperativas e os empreendimentos populares solidários que atuam diretamente no processo de coleta, de separação e de comercialização de materiais recicláveis. Segundo Missio, Alves e Vieira (2008), essa atividade econômica é considerada como de sobrevivência, pois, na sua grande maioria, é desenvolvida por desempregados que foram excluídos do sistema capitalista, tendo em vista o baixo nível de escolaridade e de acesso ao mercado formal de trabalho dessas pessoas.

Observa-se que os Empreendimentos de Economia Solidaria (EES) enfrentam dificuldades econômicas impostas pela baixa disponibilidade e eficiência das políticas públicas de controle dos resíduos sólidos nas grandes e médias cidades brasileiras. Em muitos desses EES, a renda econômica gerada para o catador é menor que o salário mínimo vigente no Brasil. Então, o desafio desses EES é atingir nível de renda que garanta aos envolvidos na atividade suprirem as suas necessidades básicas, principalmente com alimentação, saúde, lazer e educação.

A baixa renda dos trabalhadores se dá principalmente pela dificuldade da comercialização do material reciclável. Por conseguinte, os valores monetários dos materiais são determinados pelos depósitos de materiais recicláveis ou atravessadores; dessa forma, o poder de determinação de preços das cooperativas é ínfimo (CUNHA et al., 2012). 
Diante desse contexto, a instabilidade econômica, este trabalho tem como hipótese que a baixa renda dos cooperados implica em um quadro de insegurança alimentar. Essa situação ocorre, principalmente, quando o indivíduo não tem acesso regular e permanente a alimentos de qualidade e em quantidade suficiente. Tal situação relaciona-se com a vulnerabilidade social, resultante da combinação de fatores que pioram o nível de bemestar de pessoas, famílias e comunidades, ao passo que estão expostas a determinados tipos de risco (VIEIRA; FIORE; CERVATO-MANCUSO, 2006). Logo, os baixos rendimentos financeiros levariam esses indivíduos a um quadro de insegurança alimentar.

A insegurança alimentar contribui para a desmotivação dos trabalhadores e para a instauração de um ciclo da pobreza. E esse é circular e cumulativo. De acordo com Nurkse (1952 apud Myrdal, 1965), o ciclo da pobreza seria gerado quando as pessoas não têm alimentos suficientes à disposição, tornando-se subnutridas, com saúde debilitada, o que acaba limitando sua capacidade de trabalho, levando-as à pobreza; por sua vez, elas não terão o suficiente para se alimentarem, e assim por diante.

Os baixos salários levariam a condições precárias e ruins no núcleo familiar, gerando a uma baixa qualidade da alimentação (insegurança alimentar) e da saúde humana. Além disso, o que se pode observar é que os baixos salários dos catadores de material reciclável e o próprio contexto social que estes estão inseridos tende a desmotivá-los e os insere novamente no contexto de desemprego e exclusão social (CUNHA et al., 2012).

Por conseguinte, este estudo se justifica porque o ciclo da pobreza urbana se perpetua e se intensifica na presença de insegurança alimentar. $\mathrm{Ou}$ seja, essa insegurança pode implicar o aparecimento e o desenvolvimento de doenças - tais como, o agravamento de endemias, a desnutrição, as carências especificas, a obesidade, o diabetes - e outras doenças crônicas que podem causar baixo desempenho dos trabalhadores. Trabalhadores doentes tornam-se incapacitados e têm a sua capacidade laboral prejudicada; por consequência, o ciclo de pobreza é perpetuado. Sabe-se que na literatura há dificuldade em elaborar indicadores que avaliem o grau de pobreza e em programar políticas públicas eficientes que atinjam os pobres, pois o conceito de pobreza é amplo.

Nesse contexto, o presente estudo sobre insegurança alimentar e pobreza também se justifica, pois identifica fatores que podem causar e retroalimentar o ciclo da pobreza nas cooperativas de material reciclável em Goiânia. Dessa forma, este estudo também contribui com elementos para a proposição de intervenções que possam minimizar a insegurança alimentar neste ambiente. Não obstante, o objetivo geral foi verificar a relação entre a insegurança alimentar e a renda monetária nas cooperativas de reciclagem de Goiânia/GO. Especificamente, pretendeu-se, identificar 
as características socioeconômicas das cooperativas de catadores de material reciclável em Goiânia; b) verificar quais os fatores sociais e econômicos determinantes da insegurança alimentar nas cooperativas de catadores de material reciclável em Goiânia por meio do modelo Logit.

O artigo está dividido, além desta introdução, em mais quatro seções, a saber: na seção dois, foi realizada revisão de literatura sobre a pobreza e a segurança alimentar. $\mathrm{Na}$ seção três, apresentam-se os procedimentos metodológicos e o modelo econométrico Logit. $\mathrm{Na}$ seção quatro, foram apresentados e discutidos os resultados da pesquisa. Finalmente, na seção cinco, apresentaram-se as considerações finais.

\section{Pobreza e segurança alimentar}

A presente seção elucida alguns apontamentos sobre a pobreza e a segurança alimentar. Destaca-se que, a partir da revisão de literatura, dois primeiros conceitos são multidimensionais e multidisciplinares; portanto, não há consenso na literatura sobre estes temas.

\section{Apontamentos acerca da pobreza}

A respeito da pobreza, o que se observa é que esse conceito tem sofrido alterações ao longo do tempo e do modo de produção predominante no período histórico. Pontes (2010) afirma que, no período feudal, o indivíduo considerado pobre era aquele que não pertencia à nobreza ou não tinha a proteção do senhor feudal. Além disso, quase não existia mobilidade de classe, e a posição social era determinada por um "caráter divino".

Na passagem para o capitalismo, Pontes (2010) aponta que a pobreza passou a se referir à posição em relação ao trabalho. Nesse modo de produção, tal condição social era dada a aqueles que não conseguiam o bastante para viver e adquirir bens, estando relacionada ao ato de "não trabalhar". Com o desenvolvimento da industrialização e a expulsão do camponês do campo, após a queda do feudalismo, houve um grande contingente de mão de obra disponível, que não conseguia ser absorvida pela indústria, levando estes a viverem na miséria e sem trabalho. Deste modo, ao contrário do modo feudal em que era considerada uma "vontade divina", no capitalismo a pobreza acabou sendo uma consequência do modo de produção.

Entretanto, atualmente o conceito de pobreza não tem uma definição única. Pizzio (2011) observa que, na literatura, existem três ideias em torno de sua noção. A primeira baseia-se na subsistência, em que os indivíduos são considerados pobres quando suas condições materiais são insuficientes para garantir ao menos sua integridade física. $\mathrm{Na}$ segunda perspectiva, o autor destaca os meios de sobrevivência mínimos demandados coletivamente. Por fim, Pizzio enfatiza a privação relativa, que envolve aqueles que não teriam 
acesso a um regime alimentar adequado, confortos, padrões e serviços comuns na sociedade.

Lúcio (2007) nota que a pobreza possui duas medidas de mensuração: a pobreza relativa e a pobreza absoluta. A pobreza relativa refere-se à posição em que uma família ou pessoa ocupa em relação à distribuição de renda ou ao consumo de uma determinada localidade. A pobreza absoluta é vista na relação direta com a sobrevivência física. Nesta classificação, os pobres seriam aqueles que não têm renda suficiente para atender às necessidades mínimas que são predominantes na sociedade onde estão inseridos.

Nos anos 1990, o Banco Mundial se propôs a definir pobreza. Para a instituição, esta seria constituída na "incapacidade de atingir um padrão de vida mínimo” (BANCO MUNDIAL, 1990). A partir desse conceito, pode-se destacar duas questões: o que é um padrão de vida mínimo? O que é incapacidade?

Ugá (2004) afirma que o padrão de vida mínimo é aquele que permite aos indivíduos adquirirem o mínimo de nutrição necessária e outras necessidades básicas e, além disso, que contribua para que se insiram nas atividades cotidianas de uma sociedade. Para se chegar ao valor que consiga abranger esses requisitos, é necessário calcular o padrão de vida de cada localidade e, em seguida, comparar com a renda dos habitantes. Logo, aqueles que possuírem renda inferior ao necessário poderão ser considerados pobres. Por fim, a questão da incapacidade seria algo mais amplo. A autora destaca que esta pode se referir a oportunidades econômicas e à prestação de serviços sociais.

Contudo, no relatório feito pelo Banco Mundial em 2000-2001, conforme Ugá (2004), há uma alteração no conceito de pobreza. Além da forma monetária de pobreza, Ugá (2004) sinaliza que esta é incorporada à ausência de capacidades, juntamente com a vulnerabilidade do indivíduo à exposição ao risco. Essa ausência de capacidade faria com que o potencial dos indivíduos em auferir renda diminua, pois não houve investimento em seu "capital humano". Estes indivíduos seriam promovidos, por serviços de saúde que auxiliam as pessoas a terem ânimo e uma expectativa de vida melhor, principalmente, o treinamento no emprego e educação aos adultos (SAUL, 2004).

Os indivíduos que não tiveram investimentos em seu capital humano não são competitivos no mercado de trabalho, assim as dificuldades para manterem emprego aumentam e os meios para adquirirem sua subsistência diminuem. Souza-Sobrinho (2001) também vê a falta de investimento em capital humano como uma das principais causas da pobreza; afinal, os indivíduos não qualificados acabam sendo preteridos no mercado de trabalho. Além disso, por terem uma baixa qualificação, sua remuneração é inferior. 
Além do acesso dificultado à educação, os pobres vivem em um ambiente com grandes limitações. Como observado por Maia (2004), para essas pessoas faltam desde alimentação básica, água potável, habitação digna e acesso a saneamento básico. $\mathrm{O}$ autor relata ainda que, após a consciência de que tal situação é vivenciada por milhares de pessoas em diversas localidades, a Organização das Nações Unidas (ONU), decidiu reunir representantes de 189 países em setembro de 2000 que concordaram em assinar a "Declaração do Milênio".

Neste documento, encontram-se oito objetivos (erradicar a pobreza extrema e a fome; atingir o ensino primário universal; gerar igualdade de gênero; reduzir a mortalidade infantil; melhorar a saúde materna; combater doenças como HIV e a malária; garantir a sustentabilidade do meio ambiente e gerar uma parceria mundial para o desenvolvimento), que devem ser alcançados até 2015. Contudo, Maia nota que, apesar de medidas como esta, o problema da pobreza ainda continua.

Os últimos trinta anos revelaram melhorias significativas no que diz respeito ao desenvolvimento humano, mas, mesmo assim, há atualmente cinquenta e quatro países que estão mais pobres do que em 1990. Em vinte e um desses países há mais gente com fome. Em catorze desses há mais crianças a morrer antes dos cinco anos. Em doze a escolaridade diminuiu e em trinta e quatro a esperança de vida é menor. A Ásia do Sul continua a ser uma das regiões mais pobres do planeta. Sendo muito povoada concentra a maior parte dos pobres do mundo. Mais de um terço da população não tem acesso a saneamento, um terço está na pobreza, um quarto tem fome, um quinto das crianças não frequenta a escola e quase um décimo das crianças morre antes dos cinco anos. (MAIA, 2004, p.10).

Deve-se destacar que, apesar de avanços, o problema da pobreza ainda está longe de ser erradicado. Galbraith (1979) acredita que a solução para essa adversidade estaria, primeiramente, no conhecimento da causa desta para que assim se possa determinar a solução mais eficaz em cada situação. Entretanto, pode-se ressaltar que normalmente as explicações da pobreza são dadas por pessoas que vivem em países ricos; então, as diferenças tanto política quanto culturais levam as medidas sugeridas a não alcançarem o objetivo determinado.

Outra questão abordada por Galbraith (1979) é de que o interesse dos países ricos para com os pobres seria uma questão estratégica, pois estes formariam um mercado consumidor potencial para suas riquezas. Pereira $(2009$, p. 27) ressalta que as políticas sociais possuem dois lados: beneficiam os necessitados, mas sem deixar de atender a "[...] objetivos egocêntricos, como o controle social e político, a doutrinação, a legitimação e o prestígio das elites".

No caso das políticas públicas brasileiras que buscam o controle da pobreza, o que Grisotti e Gelinski (2010) ressaltam que estas se baseiam 
nas propostas elaboradas pelos governos liberais e, por isso, possuem caráter ineficiente.

[...] a política social mais recente é limitada porque se assenta naquilo que se consideram aqui como visões parciais da pobreza, isto é, aquelas que pretendem abstrair a noção de pobreza a partir do indivíduo e suas características em contraposição àquelas que localizam a pobreza como decorrente das condições estruturais. Como a pobreza é atribuída a aspectos individuais parece não haver preocupação em estruturar sistemas de proteção amplos. (GRISOTTI; GELINSKI, 2010, p. 211).

Desse modo, as políticas que têm como finalidade o combate à pobreza buscam fazer com que os indivíduos sejam inseridos nos padrões de sociabilidade vigente hoje. Além disso, o que essas medidas se propõem a solucionar são somente problemas em torno da esfera econômica. Como observado por Mauriel (2010), estas medidas fazem com que haja acomodação dos indivíduos na sua posição social.

O termo pobreza está também relacionado à exclusão e à vulnerabilidade. Essa situação seria ocasionada por fatores como desemprego, desigualdade de renda, escolaridade deficitária e incompleta, bem como pela violência. Assim, pode-se gerar um ciclo de pobreza, no qual o indivíduo, por diversos fatores, não consegue sair da situação de instabilidade.

Nos termos de Nurkse (1952 apud Myrdal, 1965), já descritos neste trabalho, a condição de pobreza seria determinante para que os indivíduos continuem inseridos nesse ciclo. E, nas palavras de Myrdal (1965): “a pobreza se torna sua própria causa”.

Procura-se encontrar fatores que possam ser geradores desse ciclo de pobreza. Myrdal (1965) crê na irrelevância de se buscar somente um fator causador desse problema, por exemplo, o fator econômico. Deve-se, portanto, observar o meio para que seja possível obter melhores respostas. O autor, ao observar a realidade do negro na década de 1950, nota que este teria baixo status por ter uma baixa escolaridade, precárias condições de saúde, menor renda, fatores que estariam associados entre si. E essa mesma realidade seria vivenciada pelos pobres.

Além dos fatores que foram citados no exemplo do negro feito por Myrdal, outra questão que leva à perpetuação do ciclo de pobreza é a acomodação. Alguns indivíduos não se sentem incentivados a mudarem a sua situação social. Como ressaltado por Galbraith (1979), a frustração gerada por não conseguirem sair da situação de pobreza é cruel, às vezes até mais perversa do que a própria condição social na qual esses indivíduos estão inseridos. $\mathrm{O}$ autor ressalta que dizer que o povo "acomodou pela própria pobreza” é algo desanimador, mas que é uma realidade frequente. 
Segundo Cardoso (2012), a disparidade de renda entre os indivíduos alimenta o "ciclo vicioso" da pobreza. A explicação para esse fato estaria na falta de integração e no próprio atraso econômico por causa de fatores como educação e mobilidade social. Essa situação levaria à geração de grandes obstáculos que corroboram para a perpetuação das desigualdades internas.

Desse modo, o Estado teria um papel importante no sentido de garantir e promover políticas que permitam quebrar e superar este ciclo. Myrdal (1965) ressalta que interferências de medidas planejadas serviriam para romper este ciclo, pois há um entrelace entre as variáveis que o causam. $\mathrm{E}$ medidas que alterem quaisquer destas ocasionariam efeitos sobre as demais. Assim, há necessidade de se criar políticas que procurem solucionar problemas educacionais, sanitários, de emprego, dentre outros, das pessoas em situação de pobreza. Melhorias no padrão de vida levariam as demais condições a progredirem, ressaltando-se que em cada localidade há um padrão de vida distinto.

\section{Apontamentos acerca da insegurança alimentar}

Apesar do pluralismo de definição do termo pobreza, pode-se afirmar que são considerados pobres são aqueles indivíduos que não conseguem adquirir o suficiente para garantir o necessário para sua sobrevivência. $\mathrm{O}$ fator mais relevante que garante sua sobrevivência é terem acesso a uma alimentação mínima e de qualidade. É a partir disso que surge a noção de segurança alimentar.

Cardoso (2010) afirma que o conceito de segurança pode ser visto sob duas perspectivas: a food safety e a food security. A food safety relacionase à necessidade de cumprir padrões de qualidade e higiene, garantindo a proteção da saúde e os interesses dos consumidores. Essa forma de segurança alimentar é a que os países desenvolvidos buscam. Já a food security está relacionada com a disponibilidade de gêneros alimentícios básicos que garantam níveis nutricionais adequados à população. Essa ideia tem sido aplicada principalmente em países em desenvolvimento.

No entanto, a definição mais geral e mais difundida em torno desse conceito dita que:

[...] segurança alimentar e nutricional como a realização do direito de todos ao acesso regular e permanente a alimentos de qualidade, em quantidade suficiente, sem comprometer o acesso a outras necessidades essenciais, tendo como base práticas alimentares promotoras de saúde que respeitem a diversidade cultural e que sejam ambiental, cultural, econômica e socialmente sustentáveis. (COTTA; MACHADO, 2013, p.54). 
O conceito está associado com a disponibilidade e o acesso em quantidade suficiente a alimentos. Cotta e Machado (2013) veem esses dois fatores relacionados à renda e às características do mercado alimentício local. Contudo, ressaltam que a questão da suficiência alimentar é algo mais complexo, que depende da inter-relação entre disponibilidade, acesso e distribuição do consumo de forma suficiente, de acordo com o tamanho e a composição familiar. Nesses termos, aqueles que não possuem acesso a uma alimentação de qualidade e suficiente estariam em situação de insegurança alimentar.

Assim como na definição de pobreza, a insegurança alimentar também teve o seu conceito associado a diversos fatores ao longo do tempo. Segundo Kepple e Segall-Corrêa (2011), nos anos 1990 o baixo peso era o fator mais usado para se determinar a insegurança alimentar. Contudo, tal noção foi considerada defasada, pois a insegurança alimentar não pode ser expressa na forma de carências nutricionais e das suas consequências físicobiológicos. Os autores ressaltam que já existem estudos que mostram que em um ambiente de insegurança alimentar pode-se encontrar a presença de indivíduos com sobrepeso. Além da desnutrição, este fator foi associado aos indicadores de produção agrícola; todavia, o que se sabe é que a escassez de alimentos não é o principal problema e, sim, o acesso a eles.

Como há um complexo número de fatores que podem gerar um quadro de insegurança alimentar e por não se ter um consenso sobre a sua incidência, a sua mensuração torna-se um desafio metodológico. Segundo Kepple e Segall-Corrêa (2011), a mensuração da insegurança alimentar no Brasil é feita por meio de estabelecimento de parâmetros de renda necessária para o consumo alimentar e não alimentar básico da população. Em geral, é estabelecido um valor monetário mínimo per capita para adquirir uma cesta básica de alimentos, além de outros itens essenciais para a sobrevivência individual, como saúde, educação, vestuário e transporte.

Entretanto, o que se observa é que a dificuldade de acesso adequado à alimentação no Brasil é vivenciada por um grande contingente da população. Em 2013, o Instituto Brasileiro de Geografia e Estatística (IBGE) realizou a Pesquisa Nacional por Amostra de Domicílios (PNAD) ${ }^{4}$, por meio da qual obteve o segundo diagnóstico sobre o tema, cujos dados são exibidos no Quadro 1.
4 A PNAD, de periodicidade anual, foi encerrada em 2016, com a divulgação das informações referentes a 2015. Todavia, no tocante à Segurança Alimentar, o último ano da pesquisa foi 2013. Assim como no primeiro estudo realizado em 2004, as estatísticas retratavam a condição de segurança alimentar nas unidades domiciliares do País tendo como referencial metodológico a EBIA, que permite identificar e classificar os domicílios pelos graus de severidade com que o fenômeno é vivenciado pelas famílias neles residentes. 
Quadro 1 - Prevalência de domicílios em situação de segurança alimentar

\begin{tabular}{|l|c|}
\hline Total de domicílios particulares & $\%$ Percentual \\
\hline Prevalência de domicílios em situação de segurança alimentar & $77,40 \%$ \\
\hline Prevalência de domicílios em situação de insegurança alimentar leve & $14,80 \%$ \\
\hline Prevalência de domicílios em situação de insegurança alimentar moderada & $4,60 \%$ \\
\hline Prevalência de domicílios em situação de insegurança alimentar grave & $3,20 \%$ \\
\hline
\end{tabular}

Fonte: IBGE (2013).

5 A Escala Brasileira de Insegurança Alimentar é composta por 15 questões, que permitem estimar as prevalências de segurança alimentar e classificar os domicílios em quatro níveis: Segurança Alimentar, Insegurança Alimentar Leve, Moderada ou Grave.
Conforme demonstra o Quadro 1, para se mensurar o grau de segurança alimentar a PNAD utilizou-se o questionário da Escala Brasileira de Insegurança Alimentar (EBIA). ${ }^{5}$ Desse modo, verificou-se que 14,80\% dos domicílios se encontravam em um ambiente de insegurança alimentar leve, 4,60\% apresentavam insegurança alimentar moderada e 3,2\% possuíam grave quadro de insegurança alimentar.

Quadro 2 - Prevalência de domicílios em situação de segurança alimentar por Cor ou Raça

\begin{tabular}{|l|c|c|}
\hline Cor ou Raça & Em situação de segurança alimentar & Em situação de insegurança alimentar \\
\hline Branca & $82,80 \%$ & $17,20 \%$ \\
\hline Preta e parda & $66,60 \%$ & $33,40 \%$ \\
\hline Amarela ou indígena & $72,10 \%$ & $27,90 \%$ \\
\hline
\end{tabular}

Fonte: IBGE (2013).

No Quadro 2, nota-se que 33,4\% dos domicílios nos quais o responsável era de categoria preta e parda experimentaram algum tipo de insegurança alimentar no período da pesquisa, enquanto os domicílios chefiados pela categoria amarela ou indígena foram de 27,9\%. Todavia, os que se autodeclararam da categoria branca foram apenas $17,2 \%$. Por fim, os resultados sugerem que as condições de escolaridade e diferença de salários entre as categorias podem estar implicando maior incidência de insegurança alimentar. Por razões econômicas e sociais, negros, pardos e indígenas estão mais vulneráveis ao desemprego e à pobreza; logo, são os mais afetados pela insegurança alimentar.

De acordo com Vinhas (2010), o problema da insegurança alimentar no Brasil é derivado de fatores socioeconômicos, como concentração de renda, baixos salários e um número alto de desempregados. Por possuir uma dimensão continental grande, esse tipo de insegurança no país se dá de forma diferenciada em cada localidade. Desse modo, faz-se necessário que se realize um estudo geográfico que busque compreender a regionalização da insegurança alimentar no Brasil, em consonância com os aspectos socioeconômicos, socioculturais e físicos, para depois realizar qualquer política de controle. 
Sobre a questão locacional, Hoffmann (1994) verifica que, em relação à desnutrição em crianças menores de cinco anos, está mais concentrada na Região Nordeste do país. Tal situação é semelhante na Região Norte, já a forma mais favorável é vista na Região Sul. Este autor observa que existem grandes diferenças regionais no Brasil; enquanto em alguns estados a situação da insegurança alimentar se compara à de países desenvolvidos, em outros a situação é a mesma vivenciada em países como o Quênia.

Entretanto, apesar da relevância do tema, somente nos anos de 1990 que os governantes passaram a se empenhar na elaboração de políticas que propagassem a segurança alimentar no Brasil, e estes objetivavam que a população tivesse acesso a alimentos de qualidade e suficientes, evitando a carência nutricional (HIRAI; ANJOS, 2007).

Em âmbito mundial, por meio dos dados obtidos pela Organização das Nações Unidas para a Agricultura e Alimentação (Food and Agriculture Organization of the United Nations - FAO), nota-se que, no período de 2010 a 2012, o número de pessoas que vivia no contexto de insegurança alimentar no mundo representava $12,5 \%$ da população. E a maioria se encontrava em países em desenvolvimento. As últimas estatísticas mostram que esse número tem sofrido decréscimo, mas não de forma tão substancial. A FAO acredita que a solução ao problema estaria no crescimento econômico dos países, pois em regiões onde este crescimento tem se dado de forma mais acelerada a redução da insegurança alimentar ocorre de forma significativa. Entretanto, a FAO ressalta que o crescimento por si só não acarrete essa diminuição.

[...] poco probable que el crecimiento por sí solo tenga un efecto considerable en la reducción del hambre. El crecimiento económico debe implicar y extenderse a los pobres mediante el aumento del empleo y otras oportunidades de generación de ingresos. Por otra parte, es preciso que las mujeres se beneficien de esas mejoras, porque cuando las mujeres tienen un mayor control sobre los ingresos de los hogares, tiende a gastarse más dinero em articulos que mejoran la nutrición y la salud. Además del crecimiento económico, para eliminar el hambre son precisas también medidas públicas. (FAO, 2012).

Hoffmann (1995) também acredita que o crescimento econômico contribua para diminuir os indicadores de insegurança alimentar. Outra solução para o combate da fome e, por consequência, da insegurança alimentar deve ser o aumento dos "direitos" dos pobres e acesso a políticas públicas, visto que, ao se tentar responder à questão da nutrição e da sobrevivência, também se estaria analisando questões da estrutura jurídica, social e econômica de uma sociedade. Desse modo, ao solucionar as falhas nestas estruturas, se permitiria aos indivíduos vulneráveis terem acesso à alimentação e uma melhoria nas suas condições de habitação, saneamento e saúde. 
Entretanto, Hoffmann (1995) ressalta que o pré-requisito de longo prazo mais eficiente estaria na educação, pois somente ela permite que as pessoas tenham uma profissão e, desse modo, se insiram na economia moderna. Contudo, enquanto essa situação ideal não se concretiza, o autor aponta a necessidade de implementar programas do governo e/ou iniciativas privadas para minimizar o problema da fome.

Apesar da relevância que o tema da segurança alimentar vem ganhando, Hirai e Anjos (2007) observam que os objetivos de redução da insegurança alimentar em âmbito mundial e nacional não estão sendo atingidos em um ritmo esperado. É possível notar que a insegurança alimentar não é causada pela falta de alimentos e sim pelas condições que permitem aos indivíduos terem acesso a estes. Logo, aqueles indivíduos que vivem em um ambiente de pobreza estariam inseridos no contexto de insegurança alimentar.

\section{Procedimentos metodológicos}

O procedimento metodológico adotado para obtenção de dados foi a pesquisa de campo a partir de amostra não probabilística definida por conveniência junto às cooperativas de catadores de material reciclável de Goiânia/GO. Este estudo em específico analisou dados obtidos em três cooperativas situadas na região norte, noroeste e leste de Goiânia, abrangendo 44 cooperados. A coleta de dados foi realizada por meio de entrevistas estruturadas.

Esse tipo de pesquisa, segundo Aguiar e Medeiros (2009), é realizado por meio de questionários que asseguram que a mesma pergunta será feita do mesmo modo a todos os entrevistados. Por isso, a escolha das perguntas se apoiou em questões que interessam a análise, dando foco aos fatores monetários que corroboram a geração de insegurança alimentar neste estudo que foram associados à renda monetária, ao número de pessoas no domicílio e à participação no Programa Bolsa Família. Também foram levantadas outras variáveis socioeconômicas, tais como: educação, idade e condição da alimentação.

\section{O modelo Logit}

O modelo Logit binomial é aplicado quando a variável dependente é dicotômica, ou seja, o fenômeno que está sendo estudado refere-se a dados que podem ser categorizados em duas classes; em nosso caso, ter ou não insegurança alimentar. As classes por conveniência têm os valores 0 e 1 , já as variáveis independentes ou explicativas podem ser de qualquer tipo de escala. 
Dessa forma, a equação (1) mostra a função de distribuição logística, onde, $=\beta_{0}+\beta_{1} X_{1 i}+\beta_{2} X_{2 i}+\beta_{3} X_{3 i}+\cdots+\beta_{k} X_{k i}$. A probabilidade de $P_{i}$ é dada por:

$$
P_{i}=\frac{1}{1+e^{-Z_{i}}}=\frac{1}{1+e^{-\left(\beta_{1} X_{1 i}+\beta_{2} X_{2 i}+\beta_{3} X_{3 i}+\cdots+\beta_{k} X_{k i}\right)}}
$$

Nessa equação pode-se verificar que $Z_{i}$ varia de $-\infty$ a $+\infty, P_{i}$ varia entre 0 e 1 , mostrando assim o caráter dicotômico do modelo que foi visto anteriormente; além disso, é observado que $P_{i}$ está relacionado não linearmente a $Z_{\mathrm{t}}$ (ou seja, $\mathrm{X}_{i}$ ). Contudo, a respeito dessa última situação, o que se nota é que, além de não ser linear em $X, \mathrm{P}_{t}$, não é linear no $\beta$. Essa situação implica que não se pode usar o método dos Mínimos Quadrados Ordinais (MQO) para estimar os parâmetros; entretanto, é possível linearizar a equação.

Dessa forma, a função de probabilidade logística acumulada pode ser especificada por:

$$
L_{i}=\ln \left(\frac{p_{i}}{1-p_{i}}\right)=\beta_{0}+\beta_{1} X_{1 i}+\beta_{2} X_{2 i}+\beta_{3} X_{3 i}+\cdots+\beta_{k} X_{k i}
$$

A variável dependente na equação de regressão é o logaritmo das chances que a escolha particular ocorre, no caso a incidência de insegurança alimentar. O modelo Logit utiliza a previsão da probabilidade no intervalo entre 0 e 1 .

Gujarati (2010) aponta as seguintes sete características do modelo Logit:

1. Quando $P$ vai de 0 a 1 (quando $Z$ varia de $-\infty$ a $+\infty$ ), o Logit $L$ vai de $-\infty a+\infty$. Entretanto, se as probabilidades ficarem entre 0 e 1 , os Logits não são restringidos.

2. Apesar de L ser linear em X, as probabilidades em si não são.

3. Neste modelo, podem ser acrescentados tantos regressores quantos forem permitidos pela teoria.

4. Se L, for positivo significa que, quando o valor do(s) regressor(es) aumenta, as chances de o regressando ser igual a 1 também aumentam. Se L, for negativo, ocorre o contrário, ou seja, as chances de o regressor ser igual a 1 diminuem à medida que o valor de $\mathrm{X}$ aumenta.

5. A interpretação do modelo, a partir da equação (1) é a seguinte: $\beta 2$, o coeficiente angular, mede a variação em $\mathrm{L}$ para uma unidade de variação em $\mathrm{X}$. $\mathrm{O}$ intercepto $\beta 1$ é o valor do logaritmo das chances favoráveis de uma situação quando $\mathrm{X}$ é igual a zero, podendo não ter qualquer sentido físico.

6. Pela equação 1 , podem ser verificadas outras situações, por exemplo, se a pessoa convive com insegurança alimentar ao invés de verificar as chances favoráveis de ter insegurança alimentar.

7. O modelo Logit supõe que o logaritmo da razão de chances esteja linearmente relacionado a $\mathrm{X}_{\mathrm{i}}$.

Após verificar as características desse modelo, podemos demonstrar como este pode ser estimado. Em nosso estudo, serão utilizados dados individuais dos cooperados; logo, a estimação por MQO por meio da equação a seguir (3) não é viável. 


$$
L_{i}=\ln \left(\frac{p_{i}}{1-p_{i}}\right)=\beta_{0}+\beta_{1} X_{1 i}+\beta_{2} X_{2 i}+\beta_{3} X_{3 i}+\cdots+\beta_{k} X_{k i}+\varepsilon_{t}
$$

Desse modo, é necessário recorrer ao método da Máxima Verossimilhança (MV) para estimar os parâmetros. Pode-se realizar tal tarefa utilizando software. No caso da pesquisa, usou-se o Evierws 7.0. Quanto aos efeitos marginais das variáveis que foram significativas, estes podem ser calculados no ponto médio dos dados para cada coeficiente estimado.

Algumas observações gerais que Gujarati e Porter (2009) apontam são:

1. O método de máxima verossimilhança, em geral, é um método de amostras grandes, terá os erros padrões estimados assintóticos.

2. Será usada a estatística $Z$ (normal) para avaliar a significância estatística de um coeficiente.

3. A medida convencional de qualidade de ajustamento não é significativa em modelos de regressando binário. Neste caso, usa-se o pseudo ou McFadden R-squared.

Por fim, a fase seguinte dessa investigação consiste na aplicação do modelo Logit aos dados obtidos por meio de questionários aplicados nas cooperativas de material reciclável de Goiânia. E os resultados são apresentados e discutidos na próxima seção do trabalho.

\section{Resultados e discussões}

Sabe-se que a teoria microeconômica tradicional do consumidor mostra como os agentes se comportam diante da variação da renda monetária e dos preços no mercado. Assim, para maiores níveis de renda, são acompanhados de aumento no consumo de alimentos. No caso da amostra estudada isto foi mais marcante, tendo em vista que esses indivíduos recebem baixos rendimentos monetários; por consequência, para qualquer variação na renda, haverá mudanças no consumo de alimentos.

Além disso, os rendimentos desses indivíduos variam muito no decorrer do ano, sendo comum o abandono da atividade para qualquer redução drástica na renda. Então, o efeito renda e substituição são predominantes sobre esses agentes, pois as mudanças cotidianas em suas cestas de consumo são ocasionadas pelas mudanças nas restrições orçamentárias e no conjunto de preços.

As variáveis e os resultados utilizados para verificar a relação entre a insegurança alimentar e a renda monetária nas cooperativas de reciclagem de Goiânia/GO encontram-se na Tabela 2:

a) $\mathrm{Y}=\mathrm{Se}$ o indivíduo se preocupou ou não com o fato de a comida acabar antes do final do mês. Essa variável dicotômica foi escolhida por representar o estado de segurança alimentar do indivíduo naquele momento, visto que as oscilações e a baixa renda dos cooperados sugerem falta de alimentos no decorrer do mês dentro de suas residências; 
b) $\mathrm{R}=$ Renda nominal mensal monetária em reais;

c) X1= Se o indivíduo participa ou não de algum programa do governo de baixa renda, no caso o Bolsa Família (variável dicotômica);

d) X2 = Número de pessoas residentes no domicílio.

Tabela 2 - Resultados estimados do modelo Logit

\begin{tabular}{c|c|c|c|c}
\hline Variável & Coeficiente Estimado & Desvio-padrão & z-Statistic & p-valor \\
\hline Constante & 1,5465 & 1,9717 & 0,7844 & $0,4328^{\text {NS }}$ \\
\hline $\mathrm{R}$ & 0,0006 & 0,0022 & 0,2767 & $0,7820^{\mathrm{NS}}$ \\
\hline $\mathrm{X} 1$ & $-1,9143$ & 0,9458 & $-2,0240$ & $0,0430^{*}$ \\
\hline $\mathrm{X} 2$ & $-0,1202$ & 0,2683 & $-0,4482$ & $0,6540^{\mathrm{NS}}$ \\
\hline
\end{tabular}

* Significativo a 1\%. NS é não significativo. McFadden R-squared = 0,093770.

Fonte: Elaborada pelos autores (2019).

Com base na Tabela 2, o coeficiente estimado para a variável renda foi pequeno e positivo; todavia, ele não foi estatisticamente significativo. Não se confirmou que a renda seria um fator determinante para reduzir a situação de insegurança alimentar. Esse resultado se deu em virtude do tamanho da amostra e da homogeneidade da renda dos indivíduos. Ademais, a variável número de pessoas residentes no domicílio também não foi estatisticamente significativa. Já o coeficiente estimado foi negativo e estatisticamente significativo para a variável participar/receber ajuda financeira de algum programa do Governo Federal, por exemplo, o Bolsa Família.

Por fim, quanto à magnitude dos coeficientes, como observado na metodologia, por se tratar de uma regressão não linear, os coeficientes apresentados na Tabela 2 não representam os efeitos marginais. $\mathrm{O}$ efeito marginal de cada variável independente para a distribuição logística pode ser obtido através da seguinte expressão a seguir. Diante dos resultados estimados, foi calculado apenas para a variável X1.

$$
\mathrm{EM}=\frac{\mathrm{e}^{\mathrm{x}^{\prime} \beta}}{1+\mathrm{e}^{\mathrm{x}^{\prime} \beta}}\left\langle 1-\frac{\mathrm{e}^{\mathrm{x}^{\prime} \beta}}{1+\mathrm{e}^{\mathrm{x}^{\prime} \beta}}\right\rangle \beta
$$

Com base na equação acima no ponto médio da variável X1, o efeito marginal encontrado foi de $-0,3943$, indicando que indivíduos que recebem ajuda financeira do governo possuem, em média, uma probabilidade $40 \%$ menor de estarem diante da situação de insegurança alimentar quando comparados aos que não recebem ajuda do programa bolsa família. Esse resultado pode ser explicado pela variabilidade da renda dos indivíduos ao longo do mês, já que o Programa Bolsa Família garante aos catadores segurança mínima na aquisição de alimentos diante da menor restrição 
orçamentária. Embora o programa não tenha sido insuficiente para mitigar os efeitos da situação de insegurança alimentar, é de suma importância. Se a causação circular não fosse pelo menos controlada geraria um quadro de desigualdades crescentes. Logo, as políticas públicas devem ser eficazes e duradouras promovendo quadro estável de renda e segurança alimentar contra os efeitos do "ciclo vicioso" da pobreza.

No estudo de Mainardes e Raiher (2018), quase todas as categorias da insegurança alimentar (leve, moderada, grave) mantêm relação com o Programa Bolsa Família. A vinculação indica que aqueles domicílios que percebem recursos desse programa têm maior probabilidade de estar na situação de insegurança. Sobre isso os autores apontam para duas hipóteses, a saber: primeiramente, que o programa atingiu o objetivo desejado, atuando exatamente nos domicílios mais vulneráveis, de modo que as famílias assistidas já estavam na condição de insegurança alimentar antes de entrar no Programa; em segundo lugar, que os recursos do programa não estão sendo suficientes para cobrir o custo calórico. Assim, Mainardes e Raiher (2018) apontaram para a restrição orçamentária das famílias, as quais, por serem vulneráveis, estariam priorizando despesas que pesam mais no orçamento, como energia elétrica, saúde, medicamentos etc., em detrimento de outras, alimentos, por exemplo. Ressalta-se que a hipótese de prioridade dos rendimentos desses autores não foi observada entre os catadores entrevistados na cidade de Goiânia.

Desse modo, o grupo estudado é composto por mulheres autodenominadas pardas, de idade média de 18 a 25 anos e que não chegaram a concluir o Ensino Fundamental. A respeito da composição familiar observou-se que esta possui quatro membros, e somente dois seriam responsáveis por adquirir renda para a residência. Além disso, neste grupo em específico, observa-se que a maior parte das famílias não possui menores de 18 anos. Já sobre a renda, o que se notou é que está é superior ao salário mínimo de 2013, e a maior parte desta é destinada a gastos com moradia. Sobre a alimentação, mais de $60 \%$ dos indivíduos analisados acreditam que possuem uma dieta balanceada, e o item mais presente nesta são as carnes.

\section{Considerações finais}

O presente estudo se propôs a verificar a relação entre insegurança alimentar e a renda monetária nas cooperativas de material reciclável em Goiânia. Para atingir tal finalidade, foram realizadas entrevistas estruturadas com 44 cooperados. $\mathrm{O}$ grupo analisado está inserido no ambiente de pobreza, pois não possui renda fixa, o que leva essas pessoas a não garantirem o suficiente para atender a suas necessidades básicas de alimentação. 
Baseando-se na teoria microeconômica do consumidor, acreditavase que o aumento no nível de renda levaria os cooperados a modificarem suas cestas de consumo. Como visto, a cesta de consumo destes indivíduos é composta principalmente por gêneros alimentícios. Logo, mudanças no nível de renda aumentariam a quantidade demandada de certos alimentos e/ ou à substituição por outros de qualidade superior, o que, por consequência, levaria a uma melhoria na dieta destes indivíduos. Contudo, o resultado do modelo Logit a respeito da relação entre insegurança alimentar e renda não confirmou que melhorias no nível de renda levam a uma diminuição do grau de insegurança alimentar nas cooperativas populares de material reciclável em Goiânia. Acredita-se que a não ocorrência desta hipótese se dá pelo tamanho da amostra e pelo fato de os cooperados obterem rendas similares entre si.

Sobre o número de pessoas por domicílio, considerava-se que quanto maior o número de pessoas residindo no mesmo local maior seria a probabilidade de se ter insegurança alimentar. Entretanto, esta variável não foi estaticamente significativa, o que não nos permite fazer inferência sobre seus resultados. A participação de programas governamentais foi estatisticamente significativa, mostrando que os beneficiários destes programas possuem menor probabilidade de se ter insegurança alimentar do que aqueles que não participam dos programas do governo. Como a renda dos cooperados não é fixa ao longo do ano, aqueles que estão inseridos em políticas governamentais de transferência de renda garantem o mínimo necessário para sua subsistência; por consequência, isso acaba reduzindo o quadro de insegurança alimentar.

Por fim, considera-se que as políticas públicas são necessárias para atenuar o grau de insegurança alimentar na vida dos catadores de material reciclável; contudo, esta não é a única fonte para a solução deste problema, devendo existir principalmente investimento na esfera educacional que proporcione aos indivíduos possibilidades de melhorias no seu padrão de vida que possibilitem a estes saírem do ciclo de pobreza.

\section{Referências}

AGUIAR, V. R.; MEDEIROS, C. M. Entrevistas na pesquisa social: O relato de um grupo de foco nas licenciaturas. In: Congresso Nacional de Educação, EDUCERE, 9., 2009, Curitiba. Anais [...]. Curitiba: PUC-PR, 2009. p. 1-9.

BANCO MUNDIAL. Relatório sobre o desenvolvimento mundial 1990: a pobreza. Rio de Janeiro: Fundação Getúlio Vargas, 1990.

BRASIL. Lei no 12.305, de 12 de agosto de 2010. Institui a Política Nacional de Resíduos Sólidos; altera a Lei no 9.605, de 12 de fevereiro de 1998; e dá outras providências. Disponível em: http://www.planalto.gov.br/ccivil_03/_ato20072010/2010/lei/112305.htm. Acesso em: 18 abr. 2019. 
CARDOSO, F. G. O Círculo Vicioso da Pobreza e a Causação Circular Cumulativa: Retomando as Contribuições de Nurkse e Myrdal. Boletim Informações Fipe, p. 13-18, ago. 2012. Disponível em: https://www.researchgate. net/publication/312374481_O_Circulo_Vicioso_da_Pobreza_e_a_Causacao_ Circular_Cumulativa_Retomando_as_Contribuicoes_de_Nurkse_e_Myrdal. Acesso em: 18 abr. 2019.

CARDOSO, M. Segurança alimentar, ajuda pública ao desenvolvimento e pobreza. In: Congresso de Ibérico de Estudos Africanos, 7., 2010, Lisboa. Anais [...]. Lisboa, 2010. p. 1-18.

COTTA, R. M. M.; MACHADO, J. C. Programa Bolsa Família e segurança alimentar e nutricional no Brasil: revisão crítica da literatura. Revista Panamericana de Salud Publica, v. 33, n. 1, p. 54-60, 2013.

CUNHA, C. A. da; DIAS, A. C.; SITONIO, D. H.; TRONCOSO, D. Ciclo Vicioso de pobreza urbana: o caso da cooperativa de catadores Beija-Flor em Goiânia, Goiás-Brasil. In: Seminário de Extensão Universitária da Região CentroOeste, 5., 2012, Goiânia. Anais [...]. Goiânia: UFG, 2012.p.1-7.

GALBRAITH, J. K. A natureza da pobreza das massas. Rio de Janeiro: Nova Fronteira, 1979.

GRISOTTI, M.; GELINSKI, C. Visões parciais da pobreza e políticas sociais recentes no Brasil. Revista Katálysis, v. 13, n. 2, p. 210-219, 2010.

GUJARATI, D. N.; PORTER, D. C. Basic Econometrics. New York: McGrawHill, 2009.

HIRAI, W. G.; ANJOS, F. S dos. Estado e segurança alimentar: alcances e limitações de políticas públicas no Brasil. Textos \& Contextos, Porto Alegre, v. 6, n. 2, p. 335-353, 2007.

HOFFMANN, R. A insegurança alimentar no Brasil. Revista Cadernos de Debate - UNICAMP, Campinas, v. 2, p. 1-11, 1994.

HOFFMANN, R. Pobreza, insegurança alimentar e desnutrição no Brasil. Estudos Avançados, v. 9, n. 24, p. 159-172, 1995.

Instituto Brasileiro de Geografia e Estatística (IBGE). Pesquisa Nacional de Amostra de Domicílios (PNAD). Segurança Alimentar 2004-2009. Rio de Janeiro: IBGE, 2010.

KEPPLE,A.W.; SEGALL-CORRÊA,A.M.Conceituando e medindo segurança alimentar e nutricional. Ciência Saúde Coletiva, v. 16, n. 1, p. 187-199, 2011.

LÚCIO, J. M. R. A relatividade do conceito de pobreza e as estratégias para a sua erradicação. Revista da Faculdade de Sociais e Humanas, Lisboa, v. 19, p. 79-98, 2007.

MAIA, D. Aplicar a ética à questão da pobreza absoluta. Orientador: Doutor João Cardoso Rosas. 2004. 166 f. Dissertação (Mestrado em Filosofia - Área de Especialização em Filosofia Moderna e Contemporânea) - Programa de PósGraduação em Filosofia e Cultura, Universidade do Minho, Braga, 2004.

MAINARDES, F.; RAIHER, A. P. (In)segurança alimentar no Brasil: prevalência e fatores associados. Cadernos de Ciências Sociais Aplicadas, [S.1.], 
p. 23, jun. 2018. Disponível em: http://periodicos2.uesb.br/index.php/ccsa/article/ view/3978. Acesso em: 18 abr. 2019.

MAURIEL, A. P. O. Pobreza, seguridade e assistência social: desafios da política social brasileira. Revista Katálysis, v. 13, n. 2, p. 173-180, 2010.

MISSIO, F.J.; ALVES, F.F.; VIEIRA, R.Economia popular solidária e precarização das relações de trabalho. Análise - Revista de Administração da PUCRS, Porto Alegre, v. 18, n. 2, p. 5-22, 2008.

MYRDAL, G. Teoria econômica e regiões subdesenvolvidas. Rio de Janeiro: Editora Saga, 1965.

NOGUEIRA JUNIOR, J. M. Políticas de gestão de resíduos sólidos: análise teórica da viabilidade econômica dos três erres. Orientador: Jorge Madeira Nogueira. 2006. 72 f. Dissertação (Mestrado em Economia) - Programa de pósgraduação em Economia, Universidade de Brasília, Brasília, 2006.

Organización de las Naciones Unidas para la Agricultura y Alimentación (FAO). El estado de la seguridad alimentaria en el mundo. Roma: FAO, 2012.

PEREIRA, P. A. Política social: temas \& questões. São Paulo: Cortez, 2009.

PIZZIO, A. O que Define os Pobres como Pobres: outros aportes ao debate acerca do conceito de pobreza. In: LUCENA, A. F. DE; CARVALHO, C. R. R.; VIEIRA, N. da M. (Ed.). Cooperação e Inclusão Social. Goiânia: PUC Goiás, 2011. p. 17-35.

PONTES, R. N. Concepções de pobreza dos atores sociais na política de assistência social no período FHC. Revista Katálysis, v. 13, n. 2, p. 181-190, 2010.

SAUL, R. P. As raízes renegadas da teoria do capital humano. Sociologias, v. 6, n. 12, p. 230-273, 2004.

SOUZA-SOBRINHO, N. Desigualdade e Pobreza: Fatos Estilizados e Simulações. Germany: University Library of Munich, 2001.

UGÁ, V. D. A categoria "pobreza" nas formulações de política social do Banco Mundial. Revista de Sociologia e Política, Curitiba, v. 23, p. 55-62, 2004.

VIEIRA, V. L.; FIORE, E. G.; CERVATO-MANCUSO, A. M. Insegurança alimentar em região de alta vulnerabilidade social da cidade de São Paulo. Segurança Alimentar e Nutricional, v. 13, n. 2, p. 34-42, 2006.

VINHAS, A. L. F. (In)segurança alimentar no Brasil: uma análise das políticas públicas dos governos de Lula. Cuadernos de Geografía, v. 19, p. 177-186, 2010.

Recebido: $27 / 09 / 2018$.

Aceito: 12/08/2019. 


\title{
THE VICIOUS CYCLE OF POVERTY AND FOOD INSECURITY IN GOIÂNIA/GO, BRAZIL
}

\begin{abstract}
The present study investigates the relationship between food insecurity and the monetary income of waste pickers from some cooperatives in the city of Goiânia, state of Goiás (GO), Brazil. To that end, 44 cooperative members were interviewed to obtain this group's socio-demographic and dietary profile. Furthermore, Logit econometric modelling indicated that an improvement in income level does not decrease the likelihood of food insecurity, thus contradicting the initial hypothesis of the present study. Among the analyzed variables, that which significantly affects food insecurity in the study is the dummy variable measuring the waste pickers' participation in government programs, which shows the importance of public policies for improving the standard of living of vulnerable groups.
\end{abstract}

Keywords: Food insecurity. Vicious cycle of poverty. Logit Model.

\section{EL CÍRCULO VICIOSO DE LA POBREZA Y LA INSEGURIDAD ALIMENTARIA EN GOIÂNIA/GO, BRASIL}

\begin{abstract}
Resumen
El presente estudio investiga la relación entre la inseguridad alimentaria y la renta monetaria de los recolectores de algunas cooperativas de la ciudad de Goiânia, GO (Brasil). Para ello, 44 cooperados fueron entrevistados para obtener el perfil sociodemográfico y alimentario de ese grupo. Además, el modelado econométrico Logit indicó que una mejora en el nivel de renta no disminuye la probabilidad de inseguridad alimentaria, contrariando la hipótesis inicial del presente estudio. Entre las variables analizadas, la que afecta significativamente la inseguridad alimentaria en el estudio es la variable dummy que mide la participación de los recolectores en los programas gubernamentales, lo que muestra la importancia de las políticas públicas para mejorar el nivel de vida de los grupos vulnerables.
\end{abstract}

Palabras-clave: Inseguridad alimentaria. Círculo vicioso de la pobreza. Modelo Logit. 